\title{
Rapid and accurate discrimination between pure and adulterated commercial Indian Honey brands using FTIR spectroscopy and principal component analysis
}

\author{
Bipin Singh ${ }^{a, b^{*}}$ and Sanmitra Barman ${ }^{a, b^{*}}$ \\ aDepartment of Applied Science, BML Munjal University, Gurugram-122413, India \\ ${ }^{\mathrm{b} C e n t r e}$ for Advanced Materials and Devices, BML Munjal University, Gurugram-122413, India
}

*Corresponding Authors Emails: bipin.singh@bmu.edu.in, sanmitra.barman@bmu.edu.in

\section{Abstract}

2 Four leading commercial Indian honey brands were investigated using FTIR spectroscopy and

3 principal component analysis for a rapid and accurate differentiation of pure, mildly

4 adulterated, and highly adulterated honey brand samples. This study is first of its kind

5 investigating commercial Indian honey brands using FTIR and PCA, hence can be used for

6 investigating adulterations in bulk commercial honey brand samples where sophisticated

7 instrumentations and facilities are not available.

8

9

10

11

\section{Keywords}

Contamination, Adulteration detection, Fourier-transform infrared spectroscopy, honey quality, Chemometrics

\section{Introduction}

Honey is sometimes adulterated by the addition of various types of sugar syrup, or compounds that change its flavour or viscosity, reduce cost, or increase the fructose content to avoid crystallization. One of the common forms of adulteration is to use sugar adulterants from C4 plants such as corn and sugarcane. Sugar adulterants from C4 plants (C4 sugar) are easier to detect due to difference in carbon isotope ratio $(13 \mathrm{C} / 12 \mathrm{C})$ compared to natural sugars that exist in pure honey [Kuan Wei, et al., 2019]. As the tests for detecting C4 sugar 
adulterations became available, now sugar adulterants from C3 plants (C3 sugar) such as rice and beetroot are reported to be used for adulteration of honey. However, detection of C3 sugar adulterations is more challenging as their $13 \mathrm{C} / 12 \mathrm{C}$ profile are like sugars in natural honey [Kropf et al., 2010; Se, Kuan Wei, et al., 2019]. However, analytical methods are developed to differentiate and detect C3 sugar adulterants in honey samples. Now there are reports that claims that new syrups for adulterations are manufactured to beat the $\mathrm{C} 3$ and $\mathrm{C} 4$ sugar tests for adulteration of honey. [Khurana et al., 2020]

In recent times the sugar adulterants became clear and almost flavourless and the adulterated mixture can be very difficult to distinguish from pure honey.

Detection of honey adulteration with C3 sugar syrups is challenging. There are two tests that check for the presence of markers specific for rice syrup to identify adulteration in honey. The SMR (specific marker for rice syrup) test check for the presence of 2-Acetylfuran-3Glucopyranoside (2-AFGP), a specific marker for rice syrups to detect the adulteration by LCMS (Liquid chromatography-mass spectrometry) based analysis. The TMR (trace marker for rice syrup) test checks the presence of arsenic traces by ICP-MS (Inductively coupled plasma mass spectrometry) based analysis in honey. Thus, both these tests can be used to detect the adulteration of honey with rice syrup (C3 sugar). [Xue, Xiaofeng, et al., 2013; Zábrodská, B. and Vorlová, L., 2015]

It is accepted that if a sample fails on any of the above tests then it shows it is adulterated by either C3 or C4 sugar. However, if the sample fails on SMR and TMR, then the source of the adulteration could be C3 sugar syrup from rice. [Khurana et al., 2020] 
Although HPLC, MS and NMR based detection methods have been shown to be effective, they are time-consuming, destructive, expensive, and require specific analytical skills, thus limiting their use in routine monitoring of adulteration in honey samples. The Indian honey market has estimated worth more than INR 1700 crore. Therefore, for high-throughput analysis of adulterations in commercial honey samples, rapid, simple, economical, and yet efficient methods have huge scope. Such approach will enable easy monitoring of the purity of commercial honey brand samples.

Previously, fourier transform infrared (FTIR) spectroscopy technique has been applied for molecular fingerprinting [Smith, 2011]. Use of principal component analysis (PCA) on FTIR spectra have been used previously to discriminate between the pure and adulterated honey samples [Rios-Corripio et al., 2012]. Earlier researchers have used FTIR for authentication of honey [Wang et al., 2010; Gallardo-Velazquez et al., 2009], however the ability of these methods in differentiating pure and mildly adulterated Indian honey brands is yet not explored as per our knowledge. Moreover, the effectiveness of this technique for detection of adulterants in leading Indian honey brands has not been performed. Therefore, for the first time, this study aims to determine the capability of PCA integrated FTIR spectroscopy for the detection and efficient separation of pure and adulterated Indian honey brand samples.

\section{Material and Methods}

\subsection{Sample collection}

A total of four commercial Indian honey brands samples were obtained from different supermarkets. All the samples were kept at room temperature before the analysis.

\subsection{FTIR Spectroscopy}


FTIR measurements in the wave number range of $4000 \mathrm{~cm}^{-1}$ to $400 \mathrm{~cm}^{-1}$ were carried out with Spectrum Two, UATR2, IR spectrometer (Perkin Elmer-2017) which was equipped with $\mathrm{LiTaO}_{3}$ detector. Between samples, the crystal was properly cleaned and dried with cleaning tissue paper. The spectral baseline recorded by the spectrometer was examined carefully to ensure that no residue or particles from the previous sample is present on the crystal. All spectra were recorded at the room temperature.

\subsection{Principal Component Analysis (PCA)}

PCA is a well-known chemometric procedure. It is an unsupervised dimensionality reduction technique that can cluster the similar data points based on the feature correlation between them. PCA uses an orthogonal transformation to convert a set of observations of possibly correlated variables into a set of values of linearly uncorrelated variables called principal components. [Popovicheva, O., Ivanov, A., \& Vojtisek, M., 2020] PCA was performed using Python and Scikit-Learn library. We have used top two principal components since they explained more than 97 percent of the total variation in the second derivative of FTIR spectra.

\section{Results and Discussion}

The following information about the possible adulteration status is available through a recent public report about the adulteration and purity of many leading Indian honey brands. [Khurana et al., 2020]

From the information provided in Table 1, if we can discriminate between these four samples using FTIR and PCA then it is possible to use these simpler methods for routine check for detecting even mild adulterations in various brands of honey samples.

Based on the observed differences in spectra of the pure and adulterated honey brand samples from Figure 1, the mid-infrared region seems suitable to identify the major 
monosaccharide and disaccharide components (Table 2). It was also confirmed that the FTIR spectra provide a clear fingerprint regarding the presence of different sugars based on differences observed in spectra of the pure and adulterated honey brand samples. We have annotated the FTIR spectra (Table 1) based on previous study [Se, Kuan Wei, et al., 2019].

The second derivative of the FTIR spectra allowed the separation of overlapping peaks and help to identify primary source of variation in different regions of the spectra. PCA is an efficient method for analysing correlation in high dimensional dataset by projecting the original data points onto lower dimensions, where it is easy to interpret the correlation using few variables. Thus, PCA can get rid of correlated components in the FTIR spectra and project the multidimensional data set to a much lower dimensionality space, often a few, or even just two dimensions, termed as principal components. Each principal component can explain some of the variation in the data. The first few principal component generally explains most of the variation.

The entire IR spectral region and IR spectral region in range of $1180-750 \mathrm{~cm}^{-1}$ was selected as the data matrix for PCA computation, wherein $1180-750 \mathrm{~cm}^{-1}$ region was shown to be sensitive for absorption for different sugar adulterants [Se, Kuan Wei, et al., 2019]. The PCA was used to evaluate the possible differences between the pure and adulterated honey brand samples. Therefore, each honey brand sample was represented by a point in the PCA plot.

Figure $2 \mathrm{a}$ and $2 \mathrm{~b}$ depicts the PCA plot for all the four honey brand samples based on whole IR spectra and spectra in the range of $1180-750 \mathrm{~nm}$. The analysis using the second derivative of the whole IR spectra and spectra in the range of 1180 to $750 \mathrm{~cm}^{-1}$ showed the efficient discrimination between the adulterated and pure honey brand samples. 
Both the PCA plots show clear and efficient separation between the adulterated (sample 3),

117 mildly adulterated (Sample 1 and Sample 2) and pure (Sample 4) honey brand samples. The observed data variation totalling up to $97 \%$ (whole IR spectra) and 98\% (1180-750nm region) was sufficient and robust to explain key variability in the spectra.

\section{Conclusion}

122 The honey brand sample possibly adulterated with only sugar syrups (Sample 1), rice and sugar syrups (Sample 2), foreign oligosaccharides, rice, and sugar syrups (Sample 3) and pure honey (Sample 4) were well segregated in PCA plots. The sample with the highest adulteration among the four honey brand samples (Sample 3) displayed the largest departure from the mildly adulterated (Sample 1 and Sample 2) and pure honey brand sample (Sample 4).

127 Therefore, it is confirmed that PCA is highly efficient in identifying the authenticity of honey brand samples in terms of clearly separating the honey brand samples that are mildly 129 adulterated and adulterated with different sugars. Thus, the potential of FTIR and PCA in discriminating the pure, mildly adulterated, and highly adulterated honey samples is validated on four Indian commercial honey brand samples and it can be further used for detecting the presence of adulterations in bulk honey samples without much cost and efforts. 


\section{Authorship contribution statement}

Bipin Singh: Conceptualization, Methodology, Formal Analysis, Writing-original draft.

Sanmitra Barman: Formal Analysis, Resources, Validation, Writing- review \& editing.

\section{Conflict of interest}

BS and SB have no conflict of interest to declare.

\section{Research Involving Human Participants and/or Animals}

Not applicable.

\section{Informed Consent}

Not applicable.

\section{References}

[1] Khurana A., Dutta A.P., Dhingra S. "The Honey Trap: Investigation into the business of adulteration of honey". Down To Earth Magazine 2020; 27-34.

[2] Kropf U, Golob T, Necemer M, Kump P, Korosec M, Bertoncelj J, Ogrinc N. Carbon and nitrogen natural stable isotopes in Slovene honey: adulteration and botanical and geographical aspects. J Agric Food Chem. 2010;58:12794-803.

[3] Li S, Zhang X, Shan Y, Su D, Ma Q, Wen R, Li J. Qualitative and quantitative detection of honey adulterated with high-fructose corn syrup and maltose syrup by using near-infrared spectroscopy. Food Chem. 2017;218:231-6.

[4] Se KW, Wahab RA, Yaacob SN, Ghoshal SK. Detection techniques for adulterants in honey: Challenges and recent trends. J Food Comp Anal. 2019;80:16-32.

[5] Xue X, Wang Q, Li Y, Wu L, Chen L, Zhao J, Liu F. 2-Acetylfuran-3-glucopyranoside as a novel marker for the detection of honey adulterated with rice syrup. J Agric Food Chem. 2013;61:7488-93.

[6] Zábrodská B, Vorlová L. Adulteration of honey and available methods for detection-a review. Acta Vet Brno. 2015;83:85-102.

[7] Smith BC. Fundamentals of Fourier transform infrared spectroscopy. CRC press; 2011.

[8] Rios-Corripio MA, Rojas-López* M, Delgado-Macuil R. Analysis of adulteration in honey with standard sugar solutions and syrups using attenuated total reflectance-Fourier transform infrared spectroscopy and multivariate methods. CyTA-J Food. 2012;10:119-22.

[9] Wang J, Kliks MM, Jun S, Jackson M, Li QX. Rapid analysis of glucose, fructose, sucrose, and maltose in honeys from different geographic regions using Fourier transform infrared spectroscopy and multivariate analysis. J Food Sci. 2010;75:C208-14.

[10]Popovicheva O, Ivanov A, Vojtisek M. Functional Factors of Biomass Burning Contribution to Spring Aerosol Composition in a Megacity: Combined FTIR-PCA Analyses. Atmosphere. 2020;11:319. 
[11] Gallardo-Velázquez T, Osorio-Revilla G, Zuñiga-de Loa M, Rivera-Espinoza Y. Application of FTIR-HATR spectroscopy and multivariate analysis to the quantification of adulterants in Mexican honeys. Food Res Int. 2009;42:313-8.

[12] Se KW, Ghoshal SK, Wahab RA, Ibrahim RK, Lani MN. A simple approach for rapid detection and quantification of adulterants in stingless bees (Heterotrigona itama) honey. Food Res Int. 2018;105:453-60. 
Table 1. Details of the honey brand samples investigated.

\begin{tabular}{|l|l|l|}
\hline $\begin{array}{l}\text { Honey Brand } \\
\text { Nomenclature }\end{array}$ & Method of Testing Adulterations & Status (Adulterated or Pure) \\
\hline Sample 1 & Passed in TMR and Failed in NMR & Possible Mildly Adulterated \\
\hline Sample 2 & Failed in TMR and NMR & Possible Mildly Adulterated \\
\hline Sample 3 & $\begin{array}{l}\text { Failed in foreign oligosaccharides } \\
\text { presence, SMR, TMR and NMR }\end{array}$ & Adulterated \\
\hline Sample 4 & Passed in TMR and NMR & Pure \\
\hline
\end{tabular}

Table 2. FTIR spectral assignment and annotation.

\begin{tabular}{|c|c|}
\hline Type of Absorption & $\begin{array}{l}\text { Absorption band and functional group } \\
\text { assignment }\end{array}$ \\
\hline $\begin{array}{l}\text { Two prominent absorption } \\
\text { bands }\end{array}$ & $\begin{array}{l}3270 \mathrm{~cm}^{-1} \text { corresponding to } \mathrm{O}-\mathrm{H} \text { stretching } \\
\text { of water. } \\
1642 \mathrm{~cm}^{-1} \text { (O-H deformation). }\end{array}$ \\
\hline Weak absorption band & $2938 \mathrm{~cm}^{-1}$ (C-H stretching of carboxylic acid) \\
\hline Weak absorption band & $\begin{array}{l}1740 \mathrm{~cm}^{-1} \text { corresponding to } \mathrm{C}=\mathrm{O} \text { stretching } \\
\text { of carbohydrates and } \mathrm{N}-\mathrm{H} \text { bending of amide } \\
\text { I of proteins. }\end{array}$ \\
\hline Multiple absorption bands & $\begin{array}{l}1500-800 \quad \mathrm{~cm}^{-1} \quad \text { (absorptions of } \\
\text { monosaccharides and disaccharides) }\end{array}$ \\
\hline Intense absorptions & $\begin{array}{l}1200 \text { to } 950 \mathrm{~cm}^{-1} \text { (C-O and C-C stretching } \\
\text { modes of carbohydrates) }\end{array}$ \\
\hline Multiple absorption bands & $\begin{array}{l}1500 \text { to } 1200 \mathrm{~cm}^{-1} \text { corresponding to } \\
\text { deformation of }-\mathrm{CH}_{2} \text { and angular } \\
\text { deformation of } \mathrm{C}-\mathrm{C}-\mathrm{H} \text { and } \mathrm{H}-\mathrm{C}-\mathrm{O} \text { linkages. }\end{array}$ \\
\hline Weak absorption band & $\begin{array}{l}920 \mathrm{~cm}^{-1} \text { corresponding to } \mathrm{C}-\mathrm{H} \text { bending of } \\
\text { carbohydrates. }\end{array}$ \\
\hline Weak absorption band & $\begin{array}{l}900 \text { to } 750 \mathrm{~cm}^{-1} \text { corresponding to } \\
\text { absorptions for anomeric carbon of sugars. }\end{array}$ \\
\hline
\end{tabular}




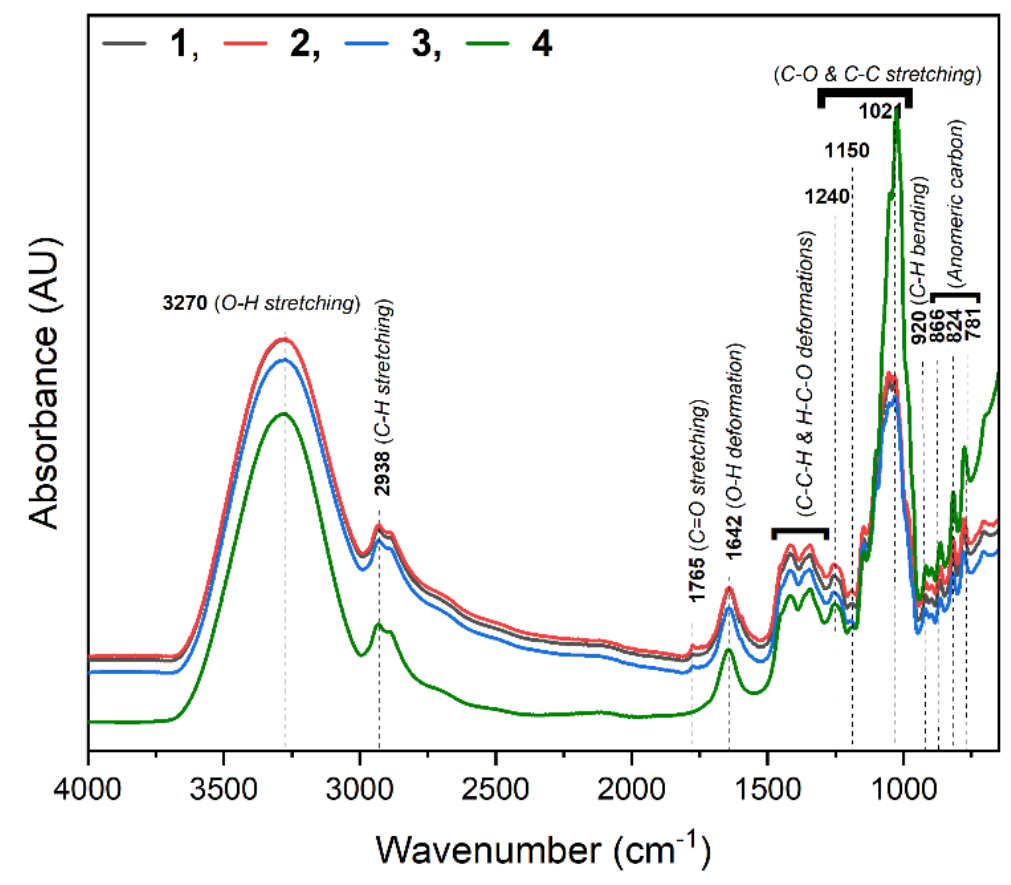

Figure 1. FTIR spectra of the four Indian honey brand samples investigated.
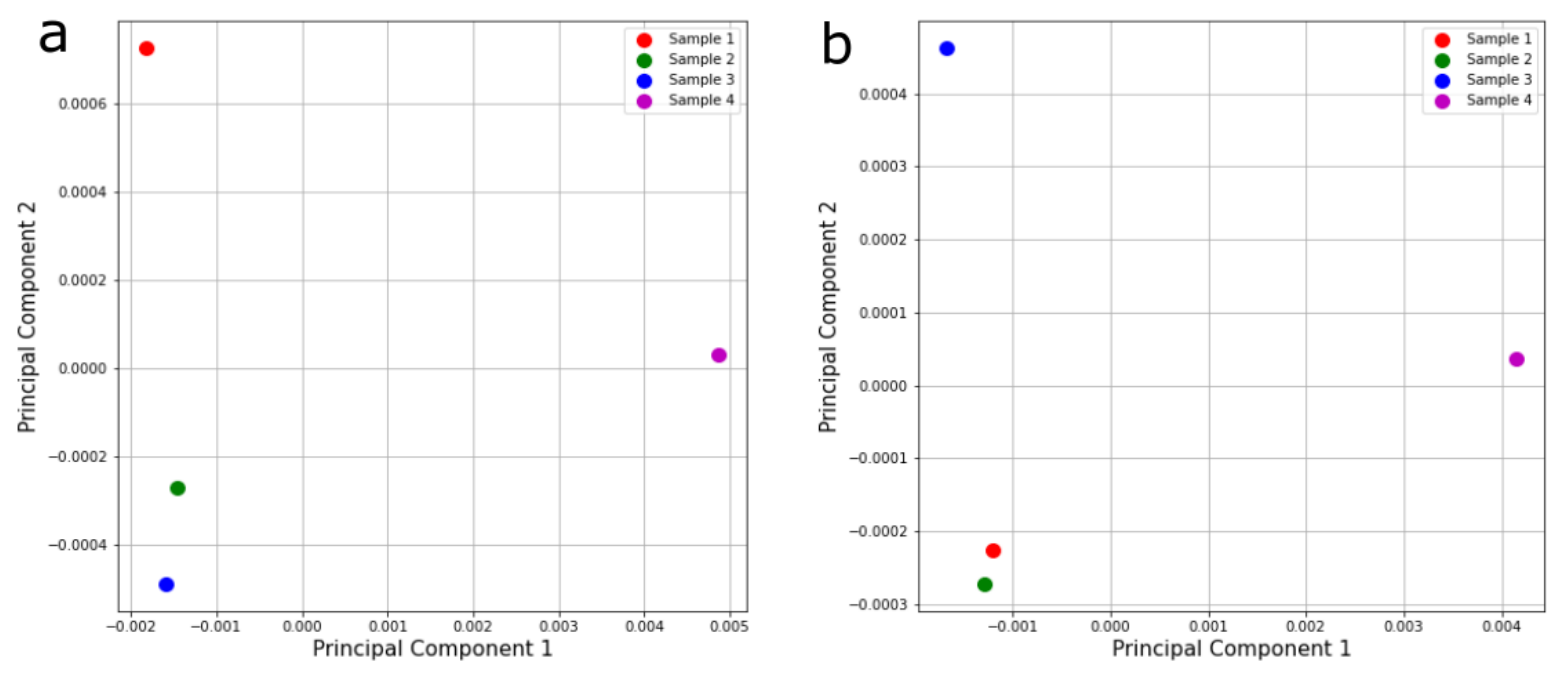

Figure 2. PCA plots for the second derivative of FTIR spectra of honey brand samples. a. Whole IR spectra PCA; b. 1180-750nm IR region PCA 


\section{Supporting information}

Figures S1-S4 show the second derivative of FTIR spectra of all the four honey brand samples.

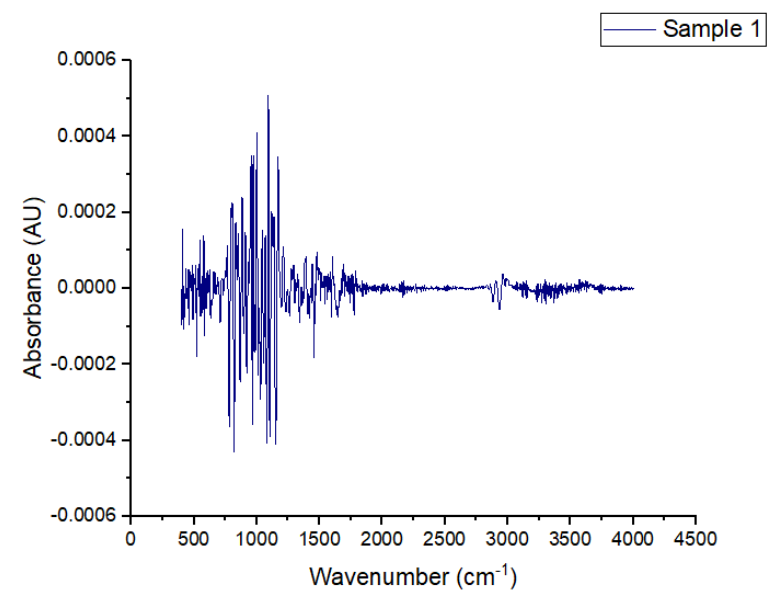

Figure S1. Second derivative FTIR spectrum of Sample 1

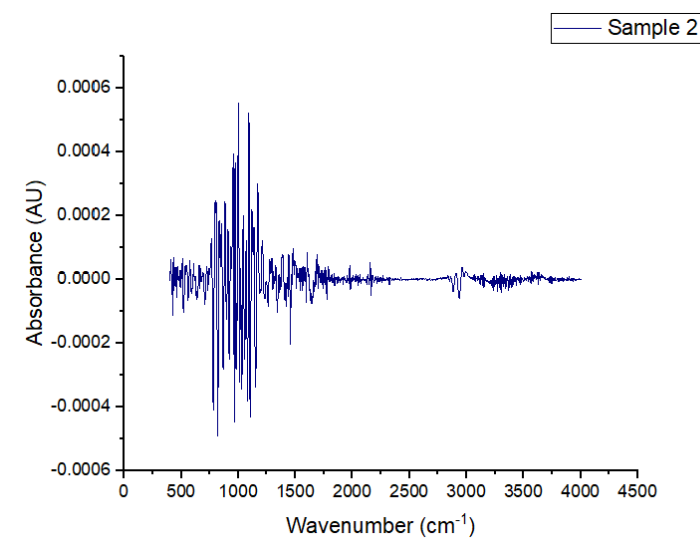

Figure S2. Second derivative FTIR spectrum of Sample 2

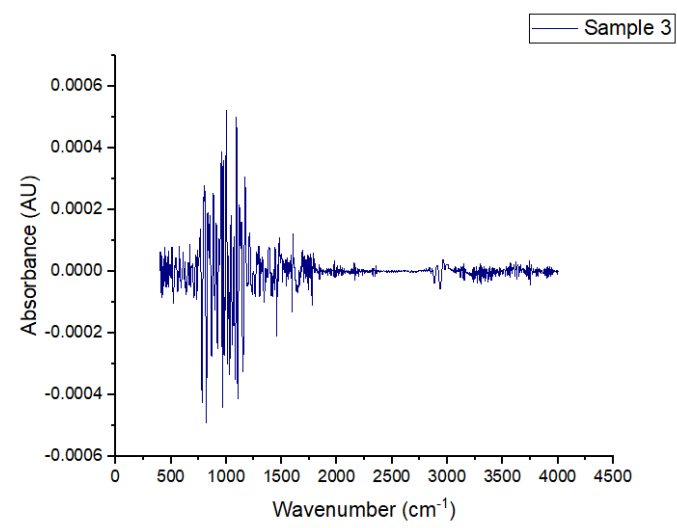

Figure S3. Second derivative FTIR spectrum of Sample 3 


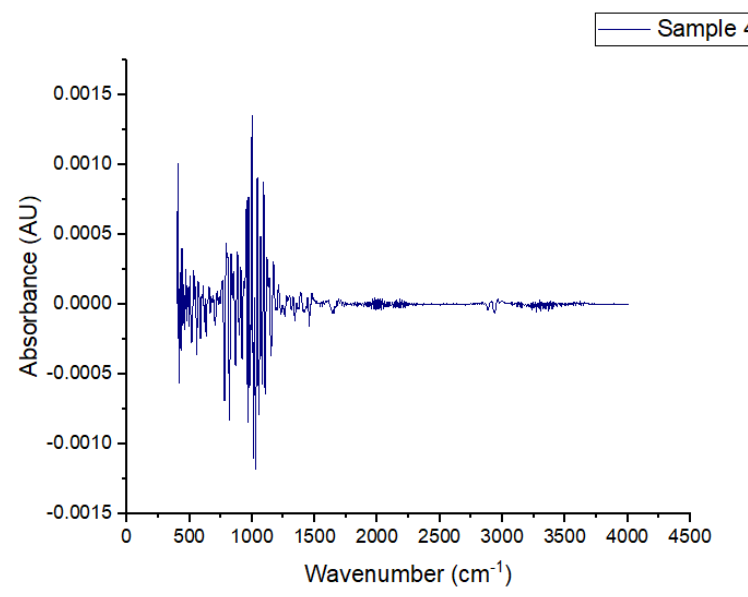

Figure S4. Second derivative FTIR spectrum of Sample 4 